\title{
DEFENDEMOS A ALEMANIA CON EL MISMO DERECHO QUE LA INFORMACIÓN LO HACE CON LOS ALIADOS: GERMANOFILIA DURANTE LA GRAN GUERRA (1914-1918)
}

\author{
WE DEFEND GERMANY WITH THE SAME RIGHT THAT LA \\ INFORMACION DOES IT WITH THE ALLIES: GERMANOPHILIA \\ DURING THE GREAT WAR (1914-1918)
}

Eugenio Quesada Rivera ${ }^{l}$ equesadar@gmail.com

Fecha de recepción: 20 mayo 2014 - Fecha de aceptación: 24 julio 2014

\begin{abstract}
Resumen
Este artículo trata de aproximarse al desarrollo de la prensa germanófila costarricense durante la Gran Guerra. El objetivo general es analizar los periódicos costarricenses que mostraron simpatía por la causa alemana entre 1914 y 1918. Se estudian las características de estos impresos, la propaganda que publican, así como también la relación que tuvieron con los periódicos aliadófilos.
\end{abstract}

Palabras claves: prensa, guerra, germanofilia, Costa Rica, Primera Guerra Mundial

\section{Abstract}

This article tries to approach the development of the Costa Rican germanophile press during the Great War. The general objective is to analyze the Costa Rican newspapers that showed sympathy for the german cause between 1914 and 1918. The work is focused in the characteristics of the papers, the published propaganda and the relationship with the ally-oriented newspapers.

Keywords: press - war-germanophilia - Costa Rica - First World War

Desde el 29 de junio de 1914, un día después de que el joven nacionalista serbio Gravilo Princip asesinara al archiduque Francisco Fernando de Austria, las páginas de los periódicos costarricenses se llenaron con las noticias del conflicto que se desataba en Europa. La magnitud de la conflagración se vislumbró desde ese mismo día: "puede suceder que esta guerra no pare en ser de Austria y Servia sino de toda Europa por los compromisos con que están ligadas ambas naciones", pregonaba el diario católico La Época en su portada.

1 Bachiller en Enseñanza de los Estudios Sociales de la Universidad de Costa Rica. Estudiante de la licenciatura en Ciencias de la Comunicación Colectiva con énfasis en Periodismo de la misma institución. Actualmente investiga la prensa germanófila en el contexto costarricense. 
La guerra, que en un inicio se esperaba durara solo algunos meses, se prolongó por más de cuatro años. Costa Rica se hallaba lejos del escenario del conflicto armado, no obstante, los responsables de los principales impresos que circulaban en su territorio asumieron pronto una posición con respecto a éste, apoyando a los Aliados (Inglaterra, Francia y Rusia) o a las Potencias Centrales (Alemania y Austria-Hungría).

La Gran Guerra -afirma la historiadora Patricia Vega- fue el primer acontecimiento mediático del siglo XX. Para entonces, los periódicos eran los únicos medios de comunicación de alcance masivo y, por tanto, los encargados de satisfacer las demandas de un público sediento de novedades sobre el desarrollo del conflicto bélico.

Este acontecimiento puso fin al sistema informativo dominante en Costa Rica desde fines del XIX, caracterizado por un dominio de la prensa política, que aparecía y desaparecía al calor de los procesos electorales (Vega, 2005: 124), una consolidación del diarismo (Vega, 2005: 129) y la instauración de la publicidad como elemento fundamental de financiamiento (Vega, 2005: 131).

Los periódicos de inicios del siglo XX tienen, por lo general, cuatro páginas, la publicidad se concentra en la portada y la contraportada, y carecen de una diagramación atractiva. En ellos la información se confunde con la opinión. Es cierto que los cables comenzaron a insertarse en la prensa de fines del siglo decimonónico, pero es la Gran Guerra la que los posiciona en un lugar de privilegio en el periódico, instaurándose así el periodismo informativo y la pirámide invertida.

Con los primeros meses de la guerra, el periodismo se verá favorecido: los periódicos aumentan las tiradas, debido a la sed informativa de la audiencia, se ensaya con nuevos géneros como el reportaje y el fotoperiodismo y se implantan los grandes titulares para llamar la atención de los lectores. Todas estas transformaciones justifican la escogencia del tema.

Así, el objetivo general de este artículo es analizar los periódicos costarricenses que mostraron simpatía por la causa alemana entre 1914 y 1918. Además, tres objetivos específicos guían la investigación: describir las principales características de los periódicos germanófilos, evidenciar la campaña propagandística que pusieron en marcha los alemanes a través de impresos costarricenses, y determinar las razones que justificaron la división entre aliadófilos y germanófilos. De este modo, se construyó un apartado para cada uno de ellos.

Se recurre a seis publicaciones: La Época, El Correo del Atlántico, Nueva Era, Pro Alemania, La Acción Social y El Correo Latino.

Se elaboró una base de datos donde se consignó el año de aparición, el de cierre, la frecuencia de publicación, la imprenta, el objetivo que buscaban, la razón de cierre y el nombre de los responsables de cada publicación periódica. Además, se revisó la mayoría de los ejemplares de cada una de ellas, para extraer noticias y comentarios que pusieran en evidencia su posición a favor del Imperio Alemán.

También se utilizan como fuentes los documentos custodiados por el Archivo Nacional de Costa Rica (ANCR) referentes a los responsables de estos impresos, el Censo Comercial de 1915 y los estudios que a nivel internacional se han escrito sobre la Primera Guerra Mundial.

\section{Antecedentes}

A lo largo de cien años, la Gran Guerra ha producido una enorme cantidad de estudios, algunos ya clásicos, como los de Renouvin (1990) y Hobsbawm (1998).

El primer autor, realiza un exhaustivo recorrido por las condiciones en las que se encontraba Europa y el resto del mundo desde 1904 hasta el estallido del conflicto, para luego adentrarse en sus detalles. De acuerdo con este académico francés, la Primera Guerra Mundial es una revolución en ciertos aspectos, que para descifrarlos es importante determinar ¿en qué medida transformó las condiciones de vida política, económica y social? (Renouvin, 1990: 8). 
Hobsbawm (1998), por su parte señala que no puede entenderse el siglo XX disociado de la guerra, esta centuria es la Época de la Guerra Total. Afirma, además, que nunca se había producido una guerra mundial, pues las otras se limitaron al espacio europeo y que éste conflicto acabó con el enorme edificio de la civilización decimonónica (Hobsbawm, 1998: pp. 30-31).

Asimismo, la guerra ha dado pie para el surgimiento de obras que se encargan de describir sus acontecimientos principales, sus causas y sus consecuencias. Dentro de ellas se pueden citar los textos de Howard (2014), Lozano (2011), Stone (2007) y Strachan (2004). Se trata de obras generales que pretenden dar al lector una primera introducción al tema.

Por una parte, la historia de la comunicación ha planteado nuevos problemas para abordar la Gran Guerra, analizando la relación entre ésta y la prensa. Se han encontrado dos tipos de estudios: los que se encargan de explicar la relación que se teje entre la guerra y la comunicación, y los que se dedican a estudiar los efectos de este conflicto en la prensa de los países neutrales.

Dentro de la primera categoría, se hallan los textos de Bordería, Laguna \& Martínez (1998); Jeanneney (2011) y Schulze (2000). Los tres autores coinciden en la importancia que tuvo el estallido de la Primera Guerra Mundial para el desarrollo de la propaganda organizada.

Pertenecen a la segunda tipología los trabajos de Betancor $(2006,2009)$, quien ha analizado la postura aliadófila del diario La Prensa de Tenerife. Román (2013), que desde una perspectiva cualitativa analiza los efectos de la guerra en La Voz de Galicia, un periódico también aliadófilo. Ponce (1992), quien determinó que la colonia alemana residente en las islas Canarias otorgaba importantes sumas de dinero al diario La Provincia. Finalmente, de la Parra (1986), comparó dos diarios mexicanos que mostraban simpatías contrarias: El Universal (aliadófilo) y El Demócrata (germanófilo). Esta autora se basa en dos acontecimientos para realizar el contraste: El telegrama de Zimmermann y El ingreso de los Estados Unidos a la guerra.

Por otra parte, en el ámbito costarricense, Vega (2007) analizó las informaciones provenientes de los dos principales diarios aliadófilos: La Información y La Prensa Libre, durante el primer semestre de la guerra. Esta misma autora $(2009,2013$ y 2014) se preocupó por comparar la manipulación informativa que se hizo en dos países centroamericanos: Costa Rica y El Salvador.

\section{Los periódicos germanófilos de Costa Rica}

Este primer apartado será dedicado a describir las principales características de los periódicos que apoyaron la causa alemana. Se intentará dar respuesta a las siguientes interrogantes: ¿Por qué surgen y desaparecen estos impresos? ¿Qué tan abierto es su apoyo al Imperio Alemán? ¿Cómo se financian? y ¿Cómo responden a las dificultades que le impone la Gran Guerra a la prensa?

Una primera característica de los impresos germanófilos es su vida efímera. Todos ellos, a excepción de La Época que apareció en 1910, vieron la luz entre 1914 y 1917 y ninguno logró sobrevivir hasta el fin del conflicto bélico, en noviembre de 1918. En esto se diferencian de los dos principales periódicos aliadófilos: La Información y La Prensa Libre, propiedad de la sociedad Clare \& Jiménez, cuyo ciclo de vida fue más largo.

El primero de esos impresos comenzó a circular en abril de 1908, mientras el segundo salía a las calles desde fines del siglo XIX. Ambos desaparecieron en 1919, tras la quema de sus instalaciones durante una protesta contra el régimen de Federico Tinoco.

El corto ciclo de vida sugiere que estos periódicos aparecieron con un propósito claro: servir de plataforma para hacer llegar a los lectores costarricenses la versión alemana de la pugna que destruía Europa. El Cuadro 1 resume los objetivos que tuvieron estos papeles públicos al nacer y sus razones de desaparición. 
Cuadro 1

Objetivos y razones de cierre de los periódicos germanófilos

\begin{tabular}{|c|c|c|}
\hline Periódico & Objetivo* $^{*}$ & Razón de cierre* \\
\hline $\begin{array}{l}\text { El Correo del Atlántico } \\
\text { 1917) }\end{array}$ & $\begin{array}{l}\text { Defender los intereses generales del } \\
\text { país y los de esta provincia (Limón) } \\
\text { particularmente. }\end{array}$ & $\begin{array}{l}\text { Alejamiento de la provincia de Limón, } \\
\text { instalación definitiva en la ciudad de } \\
\text { San José. }\end{array}$ \\
\hline El Correo Latino (1917-1918) & No indica. & No indica. \\
\hline La Acción Social (1917-1918) & Dar a conocer la acción social. & No indica. \\
\hline$(1910-1916)$ & Hacer prensa en su verdadero sentido. & Por razones que no es del caso indicar. \\
\hline$(1916-1917)$ & $\begin{array}{l}\text { Será un diario independiente en polí- } \\
\text { tica, pero respetuoso con la autoridad } \\
\text { constituida, sin malas voluntades para } \\
\text { nadie y dispuesta a ensalzar y defender } \\
\text { el bien venga de donde viniere. }\end{array}$ & Cambio en lo referente al personal. \\
\hline Pro Alemania (1916-i?) & $\begin{array}{l}\text { Defender los intereses de la causa sos- } \\
\text { tenida hoy con toda bravura y gallardía } \\
\text { por la noble Alemania. }\end{array}$ & Se desconoce. \\
\hline
\end{tabular}

${ }^{*}$ Los datos son tomados textualmente de los periódicos analizados.

Fuente: Elaboración propia a partir de datos recopilados de El Correo del Atlántico, El Correo Latino, La Acción Social, La Época, Nueva Era y Pro Alemania.

Una primera conclusión que se deriva del cuadro anterior es que los periódicos germanófilos fueron cautelosos en mostrar abiertamente su apoyo al Imperio Alemán a través de sus derroteros. Solamente la revista ilustrada Pro Alemania nació con la firme convicción de defender los intereses germanos "de esas armas, de esas bajezas, de las que se vale la prensa aliada del país para insultar de la manera más impropia a los hijos de Alemania" (Pro Alemania, 25-05-1916: 8).

No obstante a lo anterior, el apoyo al pueblo teutón se plasmó en las páginas de estas publicaciones. A inicios de diciembre de 1914, La Época, en un artículo donde replicaba unas ofensas hechas por La Información, confesaba sin rubores su germanofilia afirmando que "este periódico defiende la causa de la Nación Alemana con el mismo derecho que «La Información» lo hace con los aliados" ( $L a$ Época, 02-12-1914: 1).

Más tarde, con motivo de la aparición del periódico El Imparcial, La Época reafirmó su posición frente a la guerra, manifestando que "él será gobiernista, nosotros no; él será neutral, nosotros germanófilos" (La Época, 30-07-1915: 3). Por su parte, en El Correo del Atlántico se daba por sentado que sus lectores, por el solo hecho de leer este semanario, eran germanófilos (El Correo del Atlántico, 30-10-1915: 1).

Lo cierto es que a partir de 1916 la germanofilia comenzó a disimularse, es probable que para entonces existiera ya un clima hostil para este tipo de impresos. Las hostilidades llegarían a su punto máximo en mayo de 1918, después de que el régimen de Federico Tinoco declarara, por presiones externas, la guerra al Imperio Alemán.

Tan solo cinco días después de la declaración se emitió un decreto para reglamentar el estado de guerra, en el cual se prohibía a cualquier habitante de la República circular noticias de tendencia germanófila, pues de lo contrario sería condenado "con arresto por sesenta días o con confinamiento por seis meses, al tenor de la Ley de Orden Público de 2 de agosto de 1917" (Oficial, 1918: 351).

Este reglamento acabó con los periódicos germanófilos, que para entonces solo sobrevivían $\mathrm{El}$ Correo Latino y La Acción Social. Ambos habían negado su apoyo a Alemania. El Correo Latino, 
sucesor de El Correo del Atlántico, afirmaba que "el noventa por ciento a lo menos [de sus publicaciones] son de fuente aliadófila, tomadas... de lo que han dicho periódicos de Londres, París y New York" (El Correo Latino, 13-12-1917: 1); sin embargo, tomaban noticias de la agencia alemana Wolff y es claro que sus noticias favorecían a los germanos.

La Acción Social, por su parte, afirmaba que "sus miembros no tienen que ver en absoluto con el antiguo periódico La Época del cual solo recogió su lema de diario católico" (La Acción Social, 14-041918: 5), aun cuando su editor, Luis Cartín, fuera el mismo de aquel primer impreso. Este periódico no desaprovechó la oportunidad para exponer su punto de vista favorable respecto a la colonia alemana, tras la decisión del gobierno de Federico Tinoco de respetar las vidas y bienes de los alemanes residentes en Costa Rica:

Son los alemanes, los que mejor se han adaptado, de todos los extranjeros, a nuestras costumbres, contrayendo numerosos matrimonios con hijas de Costa Rica: títulos, todos éstos, que los hacen merecedores de la estimación y agradecimiento de todos los costarricenses (La Acción Social, 25-05-1918: 1).

Estos periódicos no tuvieron gran difusión en el mundo del periodismo costarricense, pues distribuían menos ejemplares que los producidos en las prensas de Clare \& Jiménez. Los empresarios detrás de estos impresos eran conscientes de ello, razón por la que La Época manifestaba con pesar que:

En Costa Rica, país esencialmente frívolo... natural es que tenga mucha mayor aceptación un periódico como «La Información» que ha hecho campañas ENDIOSANDO AL CRIMEN Y ESCARNECIENDO LA MORAL, que LA EPOCA, diario que sí se ha preocupado por los intereses morales del país (La Época, 12-11-1914: 1).

Visto este panorama y teniendo en cuenta que la Gran Guerra generó una situación económica hostil para el periodismo, ¿cómo se explica que estos periódicos se mantuvieran en circulación? ¿De dónde tomaban recursos si la suscripción y venta a pregón no generaban enormes cantidades de dinero?

No obstante, la colonia alemana tuvo una participación activa en estas publicaciones, no solo con escritores, como es el caso Juan Kumpel, autor de un folleto donde se culpaba a Inglaterra de haber causado la guerra (Kumpel, 1914) y de largos artículos publicados en La Época, sino también como mecenas. El Correo del Atlántico, por ejemplo, recibía mensualmente la suma de dos mil quinientos colones para su sostenimiento de parte de la colonia alemana (El Correo del Atlántico, 11-11-1916: 3).

La revista Pro Alemania negaba recibir subvención alguna de parte de la colonia germana, pero sí reconocía que "para el sostenimiento de la Revista, hemos acudido al patriotismo de los alemanes establecidos para que de esta manera ayuden a la empresa dándole sus avisos" (Pro Alemania, 15-061916: 50). Todo indica que los teutones acudieron al llamado, pues en los dos números que sobreviven de esta publicación, 46 de los 64 avisos publicados son de negocios en manos de alemanes, esto es un $71,87 \%$ del total de la publicidad.

Por consiguiente, para pautar en esta revista los miembros de la colonia alemana debían desembolsar entre ocho y treinta colones por cada edición (Pro Alemania, 15-06-1916: 62). Este patrón de financiamiento a través de la publicidad también se encuentra en los otros impresos analizados, donde no es raro encontrar los avisos de Edgar Knöhr, Guillermo Niehaus, Hermanos Steinvorth o Víctor Fabian, todos miembros de la colonia en cuestión.

Igualmente, la colonia alemana era solvente económicamente y podía contribuir al financiamiento de estos impresos. Sus miembros se dedicaron con éxito a la producción cafetalera, principal actividad de la economía agroexportadora costarricense, al cultivo del azúcar, a las finanzas o a la venta de servicios como ingenieros o técnicos. También se sabe que tuvieron una destacada actividad política (aún mayor que la de los ingleses y franceses), ocupando cargos de diputados, presidentes del Congreso, ministros o diplomáticos (Herrera, 1985).

Por su parte, el censo comercial de 1915 arroja datos interesantes que ayudan a explicar por qué los germanos residentes en Costa Rica eran capaces de financiar periódicos a través de la publicidad. 
Según este censo, en el país existían 127 comercios propiedad de alemanes, los cuales requerían anunciarse (Dirección General de Estadística, 1915). Además, los establecimientos de los teutones superaban en número a los de los franceses y los de los ingleses en casi todas las provincias, salvo en Limón y Heredia, como lo muestra el Cuadro 2.

Cuadro 2

Distribución de los establecimientos comerciales de alemanes, franceses e ingleses por provincia

\begin{tabular}{lccc}
\hline & Alemania & Francia & Inglaterra \\
\hline Alajuela & 17 & 2 & 10 \\
Cartago & 27 & 1 & 16 \\
Guanacaste & 0 & 0 & 0 \\
Heredia & 3 & 0 & 3 \\
Limón & 50 & 11 & 190 \\
Puntarenas & 0 & 0 & 7 \\
San José & 30 & 29 & 21 \\
TOTAL & 127 & 43 & 247 \\
\hline
\end{tabular}

Fuente: Elaboración propia a partir del Censo Comercial de la República de Costa Rica, 1915

Queda entonces por exponer las respuestas que ensayó la prensa germanófila ante las vicisitudes de la Gran Guerra. De los periódicos analizados el que brinda más detalles de sus adaptaciones es El Correo del Atlántico que en diciembre de 1914, a pocos días de su aparición, debió aumentar su tiraje por la buena acogida que tuvo (El Correo del Atlántico, 14-12-1914: 1). Posteriormente, sus responsables trasladaron su sala de redacción de Limón hacia Cartago, convencidos de que "al acercarnos a la capital, y por tanto al centro del país, y como quiera que encontramos más facilidades en nuestros medios de información, toda vez que podemos disponer de telégrafo, teléfono, etc." (El Correo del Atlántico, 19-03-1915: 1). Esta decisión se tradujo en un aumento significativo de las informaciones de la guerra publicadas por este impreso provinciano (Quesada, 2013: 307).

Meses más tarde, se tomó la decisión de hacer circular este impreso los días de mercado (miércoles y sábado), reforma aparejada con un aumento en el tiraje, sin que se indicara la cifra de ejemplares salidos de las prensas (El Correo del Atlántico, 07-07-1915: 3). No conforme con estos cambios, Aureliano Cámara, propietario del periódico, decidió abrir una sala de lectura en la que:

Las principales noticias que nos trasmiten el cable y el inalámbrico serán suministradas al público por medio de pizarras en nuestra oficina con algunas horas de anticipación de la llegada de la prensa de San José, que es cuando el público de Cartago acostumbra a recibirlas (El Correo del Atlántico, 28-06-1915: 1).

En las paredes de este lugar colgaban quince o veinte mapas en los que los lectores podían seguir el desarrollo de las batallas que en los campos europeos libraban las naciones beligerantes (El Correo del Atlántico, 07-07-1915: 1) (Ver Figura 1). Esta implementación no fue original, pues desde agosto de 1914 el diario La Información había instalado pizarras informativas en las afueras de sus instalaciones (Vega, 2007: 277). 


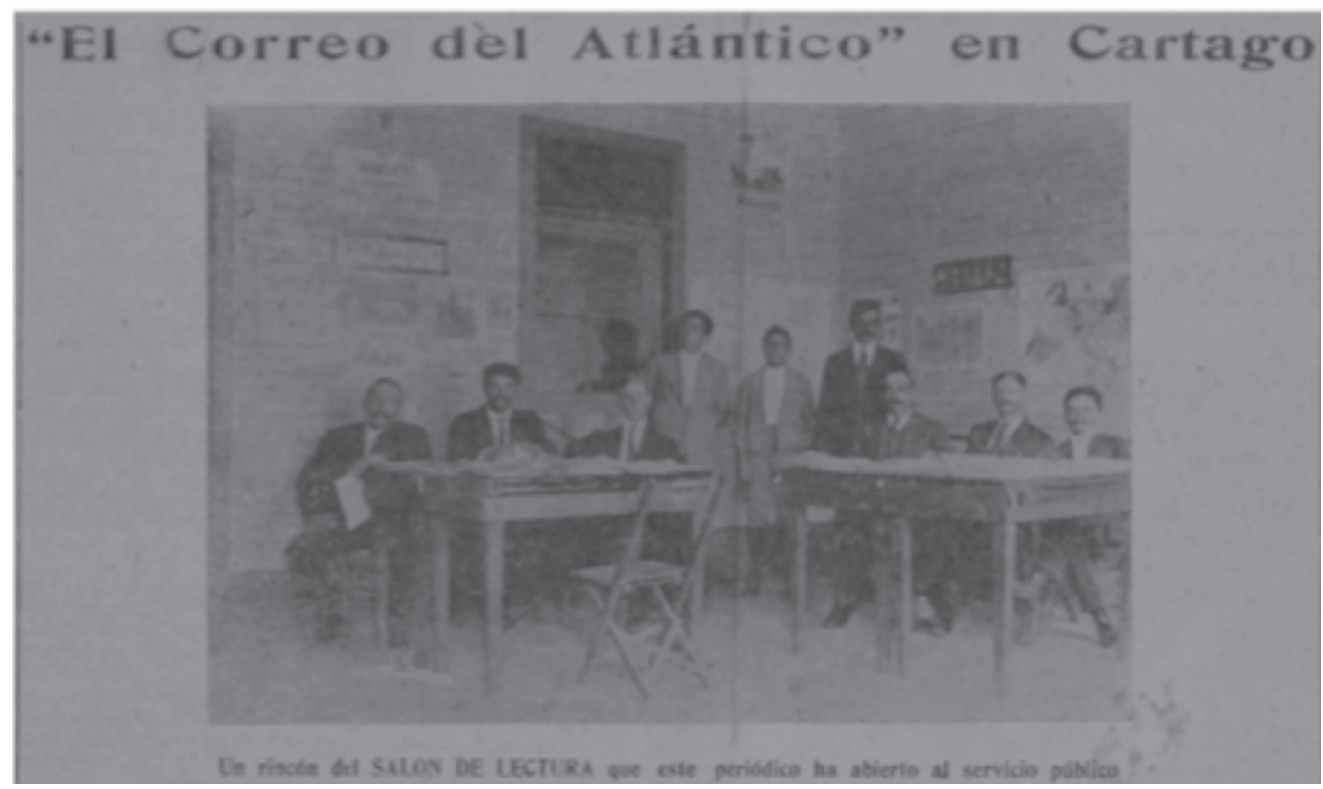

Sin embargo, no todos los cambios experimentados por los periódicos fueron positivos, también debieron hacer frente a serias dificultades, una de ellas fueron las constantes interrupciones del servicio cablegráfico que dejaba sus páginas sin noticias internacionales. No fueron pocas las veces que los responsables de los periódicos tuvieron que disculparse por no poder hacer llegar los cables a sus lectores; por ejemplo, en noviembre de 1916 Nueva Era informó que: "a la hora de cerrar la edición de hoy, 41/2 p.m., no se habían recibido las noticas cablegráficas del exterior. Deploramos, por la razón apuntada, no servirlos a nuestros lectores" (Nueva Era, 11-11-1916: 2).

Durante la guerra el papel se encareció y escaseó en gran medida, razón por la cual La Acción Social se vio obligada a reducir su formato "por haberse agotado en plaza el tamaño de papel que veníamos gastando" (La Acción Social, 05-01-1918: 1). Los efectos de la carestía de la materia prima del periódico los experimentó también Pro Alemania que se vio obligada a comunicar lo siguiente:

La administración de esta revista se permite avisar a sus suscritores [sic] y anunciantes que debido a un atraso en un pedido de papel, el número que debía salir hoy primero, se postergará al 12 de los corrientes. Pedimos, pues, las más cumplida excusas a nuestros favorecedores (La Época, 01-07-1916: 2).

\section{Propaganda de guerra alemana en los periódicos de Costa Rica}

Jeanneney (2010), afirma que la verdad fue la primera víctima de la Gran Guerra (p.135). En efecto, durante el conflicto europeo la información sufrió continuas manipulaciones, las cuales dependían de la fuente de la que provenían las noticias. En el caso de los periódicos analizados es evidente una relación con fuentes que apoyaban al bando alemán.

A su vez, los periódicos germanófilos hicieron un esfuerzo para ofrecer a sus lectores las últimas noticias de la guerra. No se conformaron con las informaciones que suministraba la Compañía del Cable, ubicada en San Juan del Sur de Nicaragua, sino que buscaron sus propios servicios informativos. 
En junio de 1915, "un suscriptor" de El Correo del Atlántico felicitaba a la redacción por "su bien montado servicio cablegráfico, que en ocasiones nos ha dado las noticias un día antes que la prensa de San José" (El Correo del Atlántico, 28-06-1915: 1).

Los elogios a los propios servicios cablegráficos suponían el menosprecio por las agencias de noticias que proveían a los periódicos aliadófilos de informaciones referentes a la guerra. Por ejemplo, en 1915 el redactor de La Época no tenía una buena opinión sobre la Prensa Asociada (principal fuente de La Información) y sostenía que:

Llegan momentos en que el criterio público habla y se dice: Prensa Asociada, equivale a Prensa Calumniosa, Circulista, Atea, Perversa, Corrompida, Temible, Despreciable, Detestable, Impía...

...En medio de la guerra más espantosa, juega con las noticias y cuenta los muertos, heridos y desastres en tono casi burlesco y mezclando lo ridículo, porque es religioso (La Época, 21-01-1915: 2).

Estos periódicos obtenían sus cables de agencias telegráficas germanófilas como la Wolff y la Transocean; las noticias transmitidas por esta última viajaban "desde Europa por inalámbrico a la Estación Radiográfica alemana de Sayville... desde allí [eran] transmitidas por cable a Guatemala, y se recibían aquí [San José] por vía telegráfica" (El Imparcial, 12-09-1915: 3). También se obtenían telegramas procedentes de Guatemala, donde los alemanes habían tenido una importante participación económica y se copiaban informaciones de periódicos como $A B C$ de España, El Cronista de Honduras y Eco Alemán de Guatemala.

Figura 2

El Correo del Atlántico, 26-01-1915: 1.
La manipulación a favor de Alemania fue constante a lo largo de los cuatro años que duró la guerra y estas seis publicaciones periódicas ayudaron a divulgarla.

El 4 de agosto de 1914 los alemanes se lanzaron contra Bélgica, nación neutral protegida por los tratados internacionales, pues les permitiría acceder con prontitud a Francia. Los belgas ofrecieron resistencia, pero fueron vencidos por los teutones y su moderna tecnología de guerra. De esta manera, comenzaba una ocupación que no acabaría sino cincuenta meses después.

Durante la invasión, los germanos se comportaron cruelmente con la población civil, se estima que al menos cinco mil civiles fueron ejecutados y más de dieciocho mil viviendas fueron destruidas (Lozano, 2011: 95). El asesinato de civiles fue admitido y promovido por los superiores del ejército alemán conscientes de la necesidad de la velocidad en el avance y con el temor a una insurrección belga (Lozano, 2011: 93).

Ante la opinión pública mundial, Alemania había quedado como una nación que no respetaba los acuerdos internacionales, ante lo

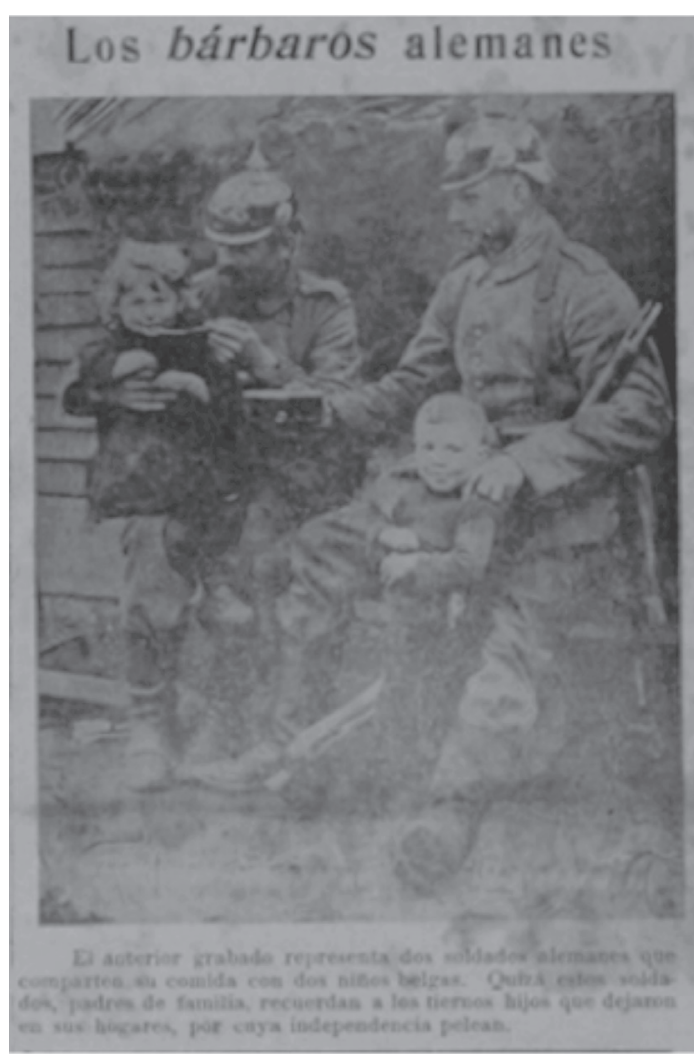


cual el 4 de marzo de 1915, El Correo del Atlántico publicó un artículo donde culpaba a Bélgica de ser la primera en violar la neutralidad:

Es indudable que Bélgica, mucho antes de la guerra, anduvo en serias negociaciones con las potencias de la Triple Entente; que tenía tratos hechos con ellas para operar guerreramente contra Alemania; que esperaba la invasión; que la violación de la neutralidad partió, por tanto, de ella misma (El Correo del Atlántico, 04-03-1915: 2).

Los países de la Entente aprovecharon estos hechos para lanzar una campaña internacional contra la "barbarie de militarismo alemán" (Castelló, 2010: 32); campaña que fue rebatida desde las páginas de los periódicos germanófilos de Costa Rica mediante la publicación de crónicas en las que se informaba que:

En efecto, los "bárbaros" alemanes se han portado en el trato con la población [belga] de manera ejemplar. En ninguna parte han dado motivos a quejas: al contrario, en muchas regiones fueron considerados y lo son todavía como salvadores del pueblo (La Época, 02-07-1915: 1).

Los fotograbados y otras ilustraciones también sirvieron a la propaganda germanófila, El Correo del Atlántico publicó una imagen con el siguiente pie de foto (Figura 2): "el anterior grabado representa dos soldados alemanes que comparten su comida con dos niños belgas. Quizá estos soldados, padres de familia, recuerdan a los tiernos hijos que dejaron en sus hogares, por cuya independencia pelean" (El Correo del Atlántico, 25-01-1915: 1).

La presencia de niños en la fotografía resulta significativa. Bordería, Laguna y Martínez (1998), señalan que en el bando aliado circularon multitud de rumores elevados a la categoría de noticias que relataban las atrocidades cometidas por los

teutones, como podían ser soldados alemanes que cortaban las manos a los niños, cocían cadáveres para fabricar jabón o crucificaban prisioneros (p. 360). Los niños cuidados por soldados alemanes es entonces una herramienta de propaganda para contrarrestar las noticias difundidas a través de los periódicos aliadófilos.

En el diario católico $L a$ Época también hay evidencias de grabados que, mediante la potencia de las imágenes, buscan convencer a los lectores de lo bondadosos que eran los soldados alemanes con los civiles belgas. La Figura 3 muestra a soldados alemanes compartiendo con mujeres y niños belgas y su pie de foto reza: "la buena amistad entre las tropas alemanas en Bélgica y la población belga".

La guerra submarina fue otro de los eventos de la conflagración que sirvió para la manipulación informativa. El 7 de mayo de 1915, el submarino U-20 hundió el Lusitania, causando la muerte de 1098 pasajeros, entre ellos 128 estadounidenses. Este acontecimiento acabó de convencer a los Estados Unidos de que tendría que entrar en la guerra contra Alemania (Strachan, 2004: 232), aunque su ingreso no se concretó hasta abril de 1917. 
Con esta acción Alemania volvía a violentar los tratados internacionales, que prohibían el hundimiento sin previo aviso de barcos civiles. Nuevamente la imagen internacional alemana se veía comprometida y esta vez con la amenaza del ingreso de los Estados Unidos a la guerra de parte de los Aliados, ante esto los periódicos germanófilos informaron que:

Alemania no tenía motivos para desear la pérdida de vidas americanas. Al contrario, el gobierno alemán ha procurado evitar tal desgracia avisando a los americanos en todos los periódicos importantes de New York que no se embarcasen en el Lusitania. De otra parte Inglaterra tuvo motivos de desear tal tragedia, a saber; llevar a los americanos a una guerra contra Alemania ( $L a$ Época, 05-06-1915: 1).

En 1917, Alemania intensificó la campaña submarina, sin embargo, la entrada de EE.UU. en el conflicto alteró de forma significativa la situación, pues se introdujeron nuevas variables, como el sistema de convoyes protegidos por buques de guerra y la utilización del hidrófono que detectaba sonidos bajo del agua (Lozano, 2011: 231). Todo esto no impidió que los impresos pro teutones publicaran textos que colocaban a Alemania en una posición aventajada:

Los alemanes están en lo justo cuando creen que su victoria está basada en la campaña submarina. Mientras ellos puedan hundir más barcos mercantes que los que las potencias aliadas puedan construir, van ellos avanzando por el camino de la victoria ( $E l$ Correo Latino, 07-03-1918: 4).

En 1918, la guerra dio un giro negativo para los alemanes. Los teutones superaban en número a los aliados, pero la balanza material se inclinaba hacia estos últimos. En marzo, se desarrolló la "Operación San Miguel” en la región de San Quintín, Francia, la cual dejó como saldo 250000 bajas en el ejército germano (Lozano, 2011: 322). En mayo, fracasaron de nuevo; esta vez las bajas ascendieron medio millón (Lozano, 2011: 325).

Así las cosas, la guerra desembocó en un tratado desfavorable para Alemania. Pese a los fracasos en los campos de batalla, los periódicos germanófilos transmitieron noticias que ponían al Imperio Alemán como el ganador del conflicto.

\section{Germanófilos vs aliadófilos: la guerra de las calumnias}

Costa Rica permaneció neutral hasta mayo de 1918, momento en que declaró la guerra al Imperio Alemán; no obstante, la población civil tomó parte del conflicto alineándose con uno u otro de los bloques enfrentados en Europa. De esta manera, los periódicos costarricenses funcionaron como una trinchera más, solo que desde éstos no se lanzaron balas, sino insultos y ofensas a quienes formaban parte del bando contrario.

Desde los inicios de la conflagración, quedaron claras las preferencias de los impresos: los diarios La Información, La Prensa Libre y La República fueron aliadófilos, mientras que los seis periódicos que se analizan en este ensayo mostraron su apoyo incondicional al Imperio Alemán.

El conflicto fue constante entre los órganos de prensa costarricenses. La defensa del bloque de preferencia se hacía con pasión llegando hasta el insulto; por ejemplo, el 24 de mayo de 1915 La Época contestaba a un artículo publicado por La Prensa Libre sobre la conducta de los oficiales alemanes que no habían recogido a los náufragos de los vapores torpedeados afirmando que:

Todos saben que estos barcos no pueden llevar más carga que la que tienen asignada pues su estabilidad en el mar peligraría si así lo hicieran. Por tanto, los submarinos no pueden recoger los náufragos porque entonces ellos también naufragarían. Si el que escribió el citado artículo conociendo este detalle se basa sobre él para extraviar la opinión pública es un MAL INTENCIONADO QUE OBRA DE MALA FE. 
Pero si desconoce este extremo, entonces es un IGNORANTE ESTÚPIDO que debiera dejar de escribir para evitar lamentables chascos (La Época, 24-05-1915: 5).

Así pues, los periódicos pro alemanes mantuvieron las mayores hostilidades con el diario $L a$ Información, al que atacaron constantemente. El Correo del Atlántico y La Época se refirieron al impreso propiedad de Clare y Jiménez como "La Inflamación" o "La Informalidad" con el propósito de ridiculizar las publicaciones que hacía.

La primera vez que se le dio el mote de "La Inflamación" fue durante la batalla de Artois, librada entre setiembre y octubre de 1915, y considerada como una de las principales ofensivas aliadas en el frente occidental durante ese año. Los aliados obtuvieron algunos avances durante este episodio y por esta razón el columnista de El Correo del Atlántico afirmaba que "en los presentes días el periódico [ $\mathrm{La}$ Información] aparece inflado, inflado y relleno" (El Correo del Atlántico, 02-10-1915: 1).

Además de los insultos, no fueron raras las acusaciones de que La Información manipulaba las noticias sobre la guerra. Por ejemplo, "el diario católico de la tarde" titulaba "En LA EPOCA no se fabrican noticias, teme La Información que se le haga competencia en ese negocio" (La Época, 16-011915: 2). Tres años más tarde, La Acción Social afirmaba que aquel era el "periódico de las noticias falsas y de la Literatura Cínica" (La Acción Social, 10-02-1918: 2).

Los periódicos germanófilos tampoco dudaron en tachar de amarillista a la prensa pro aliada, sobre todo a La Información. Por ejemplo, La Época afirmaba que ese periódico era un "diario amarillo sin más criterio ni interés por la opinión pública que el provecho monetario del trust" y el 11 de setiembre de 1915 El Correo del Atlántico indicaba que:

Los cables de Nueva York dicen que a consecuencia de la escasez de tintes y anilinas, que dicho sea entre paréntesis los aliados no han acertado a fabricar, el papel que en lo sucesivo empleen los periódicos será de un tinte amarillo. Lo cual dará ocasión para que La Informalidad y sus dos hijastras [La Prensa Libre y La República] no tengan que ocultar su color (El Correo del Atlántico, 11-09-1915: 1).

Considerando esta situación, ¿cómo se explica la división interna entre aliadófilos y germanófilos? Una primera respuesta podría estar en el apoyo que dieron los extranjeros a los periódicos de Costa Rica. Tras estas publicaciones se hallaban miembros de las naciones beligerantes; mientras en los impresos que salían de la Imprenta Moderna se atrincheraron los franceses liderados por Enrique Clare y Enrique Peyroutet, en los periódicos que mostraron simpatía por Alemania se congregaron personas como Hernán Von Bülow, Juan Kumpel y Víctor Fabian, agente representante de Bayer en Costa Rica.

Existía también una razón ideológica, los sectores conservadores y católicos se declararon germanófilos, mientras los liberales se lanzaron a la defensa de la causa aliada, grupo del principal socio comercial de Costa Rica (Inglaterra). Además, la opinión pública costarricense se escindió de manera similar a la española, situación que han señalado Betancor (2009), Laguna (2013) y Ponce (1992).

Este antagonismo quedó plasmado en un artículo titulado "Ocurrencias católicas de La Prensa Libre y otras yerbas", publicado por La Época en abril de 1915. En el texto se afirmaba que "La Prensa Libre [es] un diario de calzas anticristianas muy altas y que ha sido repetidas veces el paladín de la impiedad", pero además el autor del escrito apuntaba que este impreso estaba acostumbrado "al servilismo con las logias masónicas que en algunas ocasiones de su vida la habrán subvencionado" ( $L a$ Época, 23-04-1915: 2).

Finalmente, en esta división intervinieron las riñas personales de los dueños de los periódicos. Enrique Clare y Manuel Jiménez (dueños de la Imprenta Moderna) fueron socios de Aureliano Cámara, español y futuro propietario de El Correo del Atlántico, hasta octubre de 1914, fecha en la cual Cámara intentó cobrar a la Municipalidad de Limón la suma correspondiente a una licitación obtenida por la imprenta de Clare \& Jiménez para editar el boletín de aquella institución (ANCR, Fondo Judicial, Remesa 1563, f. 2).

Por consiguiente, la Municipalidad había acordado en junio de 1914 conceder a dicha empresa la exclusividad para editar su boletín y Cámara figuraba como intermediario. La edición constaría de 500 
ejemplares por un valor de $₫ 527.55$. Una vez terminado el trabajo, el español reclamó a sus socios su comisión, por lo que aquellos decidieron:

Pedir al Municipio que extendiera dos giros: uno a favor nuestro por $₫ 465.70$ y otro a favor del señor Cámara por $\notin 65.85 \ldots$ todo con el propósito de evitar toda clase de discusiones con ese señor. No satisfecho el señor Cámara con esa solución, en la creencia de que podía sacar mayores ventajas por su situación aparente de dueño de la licitación, nos escribión una carta diciéndonos que retiraba esa proposición y por último por mediación de don Rogelio Pardo nos hizo la oferta... en que pretende que le vendamos el Boletín por $₫ 150.00$ para hacer una modesta ganancia de $\phi 377.55$ (ANCR, Fondo Judicial, Remesa 1563, f. 5).

Como consecuencia, Clare y Jiménez rompieron su relación comercial con Aureliano Cámara y llevaron el caso a los tribunales de justicia, meses después el español apareció como propietario de $E l$ Correo del Atlántico, espacio que le sirvió para expresar su descontento contra sus antiguos socios. Esta situación desataría una verdadera guerra de calumnias.

El 3 de agosto de 1916, Peyroutet publicó un artículo en La Información recordando el segundo aniversario de la declaración de guerra a Francia. El texto estaba encabezado por la frase "Segundo aniversario del crimen alemán" y era a claras luces un insulto al Kaiser y a los alemanes. Dos días después, El Correo del Atlántico contestó a dicha publicación calumniando al ciudadano francés, afirmando que éste "tiene fama de haber estafado a la United Fruit $C^{\circ}$, cuando en dicha compañía prestó sus servicios" (El Correo del Atlántico, 05-08-1916: 4).

Clare y Peyroutet acusaron al semanario cartaginés por injuria y calumnia. Entre el 10 y el 16 de noviembre de 1916, La Información publicó una serie de artículos relacionados con la querella. El periodista Juan Rafael Escalante Roldán, antiguo empleado de Aureliano Cámara, apareció como responsable de la redacción del artículo injurioso, pero declaró que:

Uno de los primeros días del mes de Agosto último en la noche, los señores Cámara y Kumpel fueron a mi casa de habitación y me ordenaron que escribiera contra los señores Peyroutet y Clare el artículo por estos señores acusado en autos, y me suministraron los datos transcritos en él. En mi calidad de empleado del señor Cámara, lo repito, hube de cumplir con esa orden ( $L a$ Información, 10-11-1916: 2)

Estos artículos tenían la clara intención de crear en los costarricenses una opinión desfavorable hacia la colonia alemana y de ensalzar a los franceses, como queda de manifiesto en el siguiente extracto de la declaración de Escalante:

Aquella nota, en un principio, la creí yo una simple polémica de prensa, pero ahora, por motivos muy justificados, he venido al convencimiento de que tal cosa no es así, y que los señores alemanes me han tomado como instrumento valiéndose de que soy costarricense y de mi mala situación económica, para tratar de denigrar y manchar reputaciones de miembros honorables de la Colonia Francesa que, como los señores Clare y Peyroutet son dignos de toda consideración y respeto (La Información, 11-11-1916: 2).

Escalante no desaprovechó la oportunidad para injuriar a Kumpel y a sus compatriotas, por lo que agregó a su testimonio que éste le había manifestado:

Como en son de amenaza, que si yo trataba de evadir mi responsabilidad en este asunto, los alemanes me castigarían, fuera de aquí o en cualquier otro lugar en que yo me encontrara, porque ellos están muy bien organizados y temibles en todas partes del mundo (La Información, 12-11-1916: 2).

Mientras se hacían estas publicaciones, Escalante se preparaba para huir del país. Con el pretexto de no tener empleo en Costa Rica, compró un pasaje para partir hacia Colón, Panamá el domingo 12 de noviembre. Allí lo esperaba un amigo para colocarlo en un trabajo donde ganaría un sueldo mensual de \$100 (ANCR, Juzgado Civil de San José, 12250, f. 1). 
El periodista no pudo salir del país, pues la noche del 11 de noviembre fue "arrestado por el Inspector de Policía don Pedro Delgado, en la Avenida Central, á doscientas varas al Oeste del Mercado de esta Capital” (ANCR, Juzgado Civil de San José, 12250, f. 1). Según el testimonio que dio, a la mañana siguiente:

Entre ocho y nueve de la mañana, se presentaron á mi calabozo los señores don Juan Kumpel... y el Lic. don Nicolás Oreamuno, y me sometieron á un interrogatorio severo sobre mis relaciones y arreglos con los señores don Enrique Peyroutet y don Enrique Clare, caballeros honorables que se vieron en el caso de presentar acusación por injurias por la Prensa contra el semanario "El Correo del Atlántico", á causa de un artículo injurioso que yo escribí contra ellos por indicación de los señores Cámara y Kumpel (ANCR, Juzgado Civil de San José, 12250, f. 1)

Kumpel, por su parte, sostuvo en su declaración que hasta el 10 de noviembre de 1916 "no había sabido que una persona que se llama Juan Rafael Escalante Roldán existía" (ANCR, Fondo Judicial, 53241, f. 1). También negó tener injerencia en la redacción de El Correo del Atlántico, pero si era de su conocimiento que:

Escalante [era] un hombre enteramente sin recursos conocidos actualmente, [que] tomaba sus comidas en el Hotel Central, y que el dueño de ese establecimiento habia asegurado, que el valor de su mantención había sido donado para varios días adelantados por un señor Delgado, socio comercial de Peyroutet. Supe también, que se había sacado ya un tiquete para Escalante a fin de que se embarcara en el vapor "Metapán”, que el domingo siguiente había de zarpar del puerto de Limón (ANCR, Fondo Judicial, 53241, f. 19).

El alemán levantó una querella contra Escalante, Clare, Peyroutet y Ramón Zelaya por sentirse "el blanco de todo un plan de campaña difamatoria por medio de una continuada publicación de 'documentos' fabricados expresamente para el objeto" (ANCR, Fondo Judicial, 53241, f. 19). Al final, Escalante y Clare fueron encontrados responsables del delito de injurias por la prensa, por los artículos publicados en La Información y se condenó a:

Escalante a veintiún días de arresto, y a Clare, a tres días de la misma pena. El arresto se descontará en la cárcel de esta ciudad. Los dos reos deben sufrir la pena de suspensión de cargo público, durante el arresto, si alguno desempeñaren, y deben satisfacer los daños y perjuicios causados con el delito, y las costas personales y procesales del juicio (ANCR, Fondo Judicial, 53241, f. 210).

\section{Consideraciones finales}

La Gran Guerra logró captar, como nunca antes, la atención de la audiencia costarricense, que esperaba ansiosa las noticias de un conflicto que amenazaba con destruir la civilización europea. Para calmar esta sed de noticias, los distintos periódicos costarricenses debieron agenciarse un servicio informativo constante que les proveyera datos para publicar.

En Costa Rica no solo se recibieron los cables que emitía la Prensa Asociada (AP), recibidos en San Juan del Sur gracias a un convenio suscrito por los gobiernos de Costa Rica y Nicaragua en el siglo XIX, sino que también hubo presencia de agencias telegráficas alemanas como la Transocean, la Wolff y la Telefunken.

Lo anterior lleva a concluir que, al menos entre 1914 y 1918, no se cumplió a cabalidad el convenio suscrito en 1902 por el cartel de las agencias de noticias que asignaba a Centro América como zona de influencia de la AP.

Los periódicos germanófilos tuvieron por regla una vida efímera (nacieron y desaparecieron en la coyuntura de guerra) y sirvieron a la colonia alemana para difundir la propaganda que emitía el gobierno del Kaiser. En el transcurso de los cuatro años de conflicto las informaciones germanófilas sufrieron persecuciones, las cuales se agudizaron hacia el final de la guerra, cuando el contexto internacional obligó a la dictadura de Federico Tinoco a aplicar una férrea censura en contra de este tipo de periódicos. 
De este modo, la colonia alemana de Costa Rica, al igual que las residentes en otras latitudes, puso en marcha un proyecto de comunicación que tenía como propósito dar su propia versión de la guerra y, al mismo tiempo, ganar adeptos que apoyaran su lucha. Para lograr sus objetivos, los teutones desembolsaron importantes sumas destinadas a financiar la circulación de periódicos pro-germanos.

En fin, la Primera Guerra Mundial desató las pasiones de extranjeros y naturales, razón por la cual en suelo costarricense se libró una auténtica batalla de injurias y calumnias, que llegó al extremo de perseguir y encarcelar periodistas por el simple hecho de publicar informaciones y opiniones contrarias a quienes apoyaban al bloque contrario.

\section{Referencias}

Betancor, O. (2006). La Primera Guerra Mundial a través de las páginas del periódico "La Prensa". Tebeto, Anuario del Archivo Histórico Insular de Fuerteventura, (19), 138-157.

Betancor, O. (2009). La postura aliadófila del diario La Prensa durante la Primera Guerra Mundial. Anuario de Estudios Atlánticos, (55), 343-365.

Bordería, E.; Laguna, A \& Martínez, F. (1998). Historia de la Comunicación Social. Voces, registros y conciencias. Madrid: Síntesis.

Castelló, J. (2010). La Primera Guerra Mundial. La Gran Guerra. Madrid: Anaya.

De la Parra, Y. (1986). La Primera Guerra Mundial y la prensa mexicana. Estudios de Historia Moderna y Contemporánea de México, 10. Disponible en: http://www.historicas.unam.mx/moderna/ehme/ fichas/f128.html

Dirección General de Estadística. (1915). Censo Comercial de la República de Costa Rica. San José: Imprenta Nacional.

Herrera, E. (1985) "Los inmigrantes y el poder en Costa Rica", Revista de Historia, N 11, 146-147.

Hobsbawm, E. (1998). Historia del siglo XX. Buenos Aires: Crítica.

Howard, M. (2014). La Primera Guerra Mundial. Barcelona: Crítica.

Jeanneney, J. (2011). Une histoire des médias. Paris: Éditions Points.

Kümpel, J. (1914). La Guerra. Su origen histórico, su verdadera causa y los pretextos con que los enemigos de Alemania excusan su agresión. San José: Tipografía Lehmann.

Laguna, A. (2013). Efectos de la Gran Guerra en la prensa valenciana: un cambio de ciclo. Historia y Comunicación Social, Vol. 18, 275-291.

Lozano, A. (2011). Breve Historia de la Primera Guerra Mundial. Madrid: Nowtilus.

Oficial. (1918). Colección de Leyes y Decretos de Costa Rica. San José: Tipografía Nacional.

Ponce, J. (1992). Prensa y germanofilia en Las Palmas durante la Gran Guerra. Anuario de Estudios Atlánticos, Vol. 1 (38), 581-602.

Quesada, E. (2013). Informar la Gran Guerra desde un periódico local. El caso de El Correo del Atlántico (1914-1917). Historia y Comunicación Social, Vol. 18, 305-321.

Schulze, I. (2000). Guerra y Comunicación: una relación compleja. En: Gómez, J \& Marín, E. (Ed.). Historia del Periodismo Universal. Madrid: Síntesis.

Stone, N. (2008). Breve Historia de la Primera Guerra Mundial. Barcelona: Ariel.

Strachan, Hew. (2004). La Primera Guerra Mundial. Barcelona: Crítica.

Renouvin, P. (1990). La crisis europea y la Primera Guerra Mundial. Madrid: Akal.

Román, M. (2013). Aliadofilia y neutralidad de La Voz de Galicia en los años de la Primera Guerra Mundial. Historia y Comunicación Social, Vol. 18, pp. 293-303.

Vega, P. (2005). La prensa costarricense en tiempos de cambio. Revista de Ciencias Sociales, (108), 121-144.

Vega, P. (2007). Primicias de la Primera Guerra Mundial en la prensa costarricense (1914). Inter.c.a.mbio, (5), 271-308. 
Vega, P. (2009). ¿Especulación desinformativa? La Primera Guerra Mundial en los periódicos de Costa Rica y El Salvador. Mesoamérica, (51), 94-122.

Vega, P. (2013). La guerra como espectáculo mediático. La prensa centroamericana en la Gran Guerra (1917). Historia y Comunicación Social, Vol. 18, 43-61.

Vega, P. (2014). Guerra, prensa y manipulación informativa: La prensa de Costa Rica y El Salvador en el segundo semestre de la Primera Guerra Mundial. En: Valles, R.; González, R. \& Vega, P. (Coord.). La prensa un actor sempiterno: de la Primera Guerra Mundial a la Posmodernidad. México: Gernika. 
